\title{
The [overestimated] role of strategic orientations for international performance in smaller firms
}

\author{
Frishammar, Johan \\ Luleå University of Technology \\ Andersson, Svante \\ Halmstad University
}

\section{Extended Abstract}

This study examines how market orientation (MO) and entrepreneurial orientation (EO) relate to international performance in a large sample of smaller manufacturing firms. Several previous studies look at MO or EO but do not combine them in a single research design. Previous research by Tzokas et al. (2001) also indicate that both $\mathrm{MO}$ and $\mathrm{EO}$ are important to the performance in SMEs, but knowledge on how they impact on international performance is limited. We therefore look specifically at smaller firms, where research on strategic orientations and international performance to a large extent is lacking. Previous research has also focused mainly on concepts such as international entrepreneurial orientation and international marketing orientation (e.g. Knight \& Cavusgil, 2004). The fact that these orientations positively influence firms' international performance is not surprising since dependent and independent variables are to some extent similar and can be viewed as at least partly tautological. Therefore, in this study, our aim is to see if conceptualizations of market- and entrepreneurial orientation excluding international aspects are associated with international performance. Our paper also draws on data collected from firms in Sweden, where this kind of empirical research has not yet been conducted.

For testing our four hypothesis - that is, how market orientation and three components of an entrepreneurial orientation relates to international performance - we draw upon a sample of 188 smaller firms, where the average firm had 98 employees. For testing the actual hypotheses, we used regular multiple regression analysis, preceded by an exploratory factor analysis for scale purification purposes, and the regular/conventional tests of reliability for all scales. Our results from testing the hypotheses are best described as "non-results" and show that strategic orientations has a very limited influence on international performance, indicated by only a very small percent of the variance in international performance explained by strategic orientations. More specifically, proactiveness and, to some extent, a market orientation proved positively associated with international performance while no association was found for the links between innovativeness and risk taking and international performance. 
The main conclusion presented is that strategic orientations are insufficient to explain variations in how firms perform internationally. Specifically, we conclude that the absence of correlations between $\mathrm{MO}$ and international performance could be due to the fact that firms use marketing in such a general and informal way that it does not impact on performance. Also, the MO construct focuses on systematic procedures at the expense of more "informal" ones. Consequently, smaller firms might be better off "learning-by-doing" through international activities than engaging in formal marketing research. In addition, the international markets of firms might also change at a pace too quick for formal marketing research to pay off. Firms thus need to know that markets can both mislead and misinform, as new information and knowledge about these markets can be outdated rapidly.

Furthermore, we did not find any significant association between innovativeness and international performance. The fact that our measure of innovativeness focus on product- rather than market innovation is a likely cause of this, and we conclude that it might be difficult for smaller firms to focus simultaneously on product- and market innovation. Similar results were found regarding the link between risk-taking and international performance. As smaller firms usually have a smaller resource-base, we conclude that they can benefit from choosing internationalization strategies with a lower amount of risk, such as direct export or agents. Proactiveness influenced international performance positively, however, a finding in line with much of the extant literature. Hence, proactiveness combined with a low-risk entry mode approach could be an efficient way to reach high international performance for smaller firms active on international markets. 